\title{
A parentalidade corresponsável e a maternidade por sub-rogação: uma análise a partir do enfoque jurídico dos sistemas normativos brasileiro e português
}

\author{
Co-responsible parentality and maternity by subrogation: an analysis from the \\ legal approach of Brazilian and Portuguese regulatory systems
}

\author{
Gabrielle Bezerra Sales Sarlet ${ }^{\star}$ \\ Denise Almeida de Andrade ${ }^{* *}$
}

\section{Resumo}

A reprodução humana é tema que desperta o interesse das diversas áreas do conhecimento e, durante as últimas quatro décadas, tem inaugurado discussões cada vez mais densas, tendo em vista os avanços tecnológicos que alteraram os seus parâmetros. Este artigo objetiva contribuir para a densificação das reflexões sobre os efeitos da reprodução assistida nas relações parentais, a fim de propor algumas pautas de solução para os conflitos da contemporaneidade concernentes à parentalidade em situações em envolvem a maternidade por sub-rogação de útero. Para alcançar esse fim, restou a opção pela pesquisa eminentemente teórica, bibliográfica, exploratória e mediante emprego do método hipotético-dedutivo para alcançar o intento de traçar um contorno jurídico geral das técnicas de reprodução assistida a partir de uma perspectiva de constitucionalismo multinível e em especial de direito comparado, enfatizando, nesse intento, os regramentos atinentes à maternidade por substituição, para provocar um confronto entre o vácuo de regulamentação brasileira e o posicionamento recente do Tribunal Constitucional Português.

Palavras-chave: Maternidade por substituição. Direitos humanos e fundamentais. Planejamento familiar. Parentalidade.

\section{Abstract}

Human reproduction is a theme that arouses the interest of the various areas of knowledge and during the last four decades has opened increasingly dense discussions, in view of the technological advances that have altered the parameters of reproduction, with all the possibilities known today of assisted reproduction. This article aims to contribute to the densification of the reflections on the effects of assisted reproduction in parental relationships, in order to propose some guidelines for the contemporary conflicts concerning parenthood in situations involving maternity by subrogation of the uterus. In order to achieve this aim, we opted for theoretical, bibliographical and exploratory research and using the hypothetical-deductive method, we tried to draw a general legal outline of assisted reproduction techniques from a perspective of multilevel constitutionalism and especially comparative law, emphasizing the regulations regarding maternity by subrogation, to provoke a confrontation between the vacuum of Brazilian regulation and the recent position of the Portuguese Constitutional Court.

Keywords: Maternity by Subrogation. Human and fundamental rights. Family planning. Parentality.

\section{Introdução}

Passados mais de trinta anos da promulgação da Constituição Federal de 1988, que, entre outros avanços, intentou empreender um catálogo condizente com a construção de um panorama solidário, responsável e, em especial, mais inclusivo, é pungente afirmar que, no que toca ao direito ao planejamento familiar e, sobretudo, à regulamentação das modalidades de reprodução assistida, ainda resta muito esforço a ser encetado pelo jurista contemporâneo para a sua concretização.

* Doutora em Direito pela Universidade de Augsburg - Alemanha. Graduada e mestre em Direito pela UFC - Universidade Federal do Ceará. Advogada e Consultora Jurídica. Porto Alegre - RS - Brasil. E-mail: gabriellebezerrasales@gmail.com.

** Pós-doutoranda em Direito Público e Econômico pela Universidade Presbiteriana Mackenzie (PNPD-CAPES). Doutora e Mestre em Direito Constitucional pela Universidade de Fortaleza - UNIFOR. São Paulo - SP- Brasil. E-mail: andradedenise@hotmail.com. 
O contexto brasileiro, além de todas as alterações advindas a partir do atual paradigma constitucional, pautado no princípio da dignidade da pessoa humana, implica posturas receptivas e concretas em relação aos apelos evocados da composição atual da sociedade civil, principalmente no que afeta à garantia dos direitos sexuais e reprodutivos em uma tessitura ampla que contemple e agregue o maior número de atores sociais. Incontestável, nessa altura, é mencionar a relevante contribuição dos movimentos sociais emancipatórios, gerando expressivas demandas por direitos por parte das camadas da população violentadas e vulnerabilizadas.

Em rigor, não se deve olvidar que reproduzir é verbo transitivo e, nesse sentido, somente pode ser conjugado na forma pronominal, ou seja, a reprodução evoca desdobramentos e, destarte, consiste em temática de extrema complexidade.

Importa, nesse sentido, relembrar que, particularmente no que tange aos efeitos eficaciais no âmbito nacional, a busca pela efetividade dos direitos sexuais e reprodutivos se torna cada vez mais nuclear e urgente. Assim, essencial é valorizar as oportunidades de diálogo livre que, em uma perspectiva lúcida, encetem esforços para a aproximação dos textos legais às demandas sociais, impedindo uma interpretação eminentemente biomédica, que tem sido utilizada para suprir as lacunas como tem ocorrido até a atualidade.

Este artigo, por meio de pesquisa eminentemente teórica, bibliográfica, exploratória e mediante emprego do método hipotético-dedutivo, intenta clarificar o estado da arte no que concerne às técnicas de reprodução assistida a partir de uma perspectiva de constitucionalismo multinível e, em especial, de direito comparado, enfatizando, nesse intento, as possibilidades de maternidade por substituição, para provocar um confronto entre o vácuo de regulamentação brasileira e o posicionamento recente do Tribunal Constitucional Português.

Objetiva contribuir para o adensamento do diálogo acerca dessa matéria e, assim, propor algumas pautas de solução para os conflitos da contemporaneidade (DW, 2018, on-line) no que concerne ao tema. Para alcançar esse fim, entende-se que investigar experiências estrangeiras pode ser útil na proposição de opções para o Brasil, optando-se pelo direito português como ponto de inflexão dessa análise comparativa.

\section{O panorama atual das técnicas de reprodução assistida com ênfase nas atuais modalidades e efeitos da maternidade por substituição}

Saúde reprodutiva diz respeito a um estado além do padrão curativo e preventivo, além do binômio saúde-doença, que, em síntese, se concretiza quando as pessoas podem desfrutar de uma vida plena, assumindo posturas responsáveis em uma conjuntura segura para expressar livremente a sua autonomia mediante a mais apropriada qualidade e quantidade de informações acerca das técnicas, dos efeitos de seu emprego e dos padrões éticos que justificam ou legitimam o seu uso.

Interessante perspectivar, nesse sentido, a ideia de infertilidade, entendendo-a como um conceito que tem sofrido inúmeras modificações e que pode ser diretamente atrelado às atuais modulações acrescidas ao conceito de família. De todo modo, infertilidade é definida pela Organização Mundial da Saúde (OMS) como: "a incapacidade de um casal para alcançar a concepção ou levar uma concepção a termo após um ano ou mais de relações sexuais regulares, sem proteção contraceptiva" (OMS, 2019, on-line). Isto acontece porque só ao final de um ano de relações sexuais regulares desprotegidas é que a probabilidade de um casal conceber um filho é de $100 \%$ (cem por cento), uma vez que essa probabilidade é calculada mensalmente e acumula ao longo dos meses, chegando aproximadamente aos $100 \%$ (cem por cento) ao fim dos 12 meses (OMS, 2019, on-line).

De modo geral, torna-se necessário relembrar que há quarenta anos houve uma verdadeira clivagem na área da reprodução humana advinda do nascimento de Louise Brown. ${ }^{1}$ Com efeito, a reprodução

O nascimento da Louise Brown pode ser entendido como um marco historicamente relevante na civilização ocidental em razão do uso da biotecnologia na área da reprodução humana, mas especialmente pela excessiva exposição a qual tem sido submetida ao longo desses quarenta anos, desde a sua concepção, afetando sua privacidade e introduzindo uma forma distinta de organização da vida privada desde então (BBC, 2019, on-line). 
humana ganhou em sentido e em complexidade, na medida em que se aliou ao padrão natural o padrão da artificialização (ANDERSON; RAINIEL; LUCHSINGER, 2019, on-line). O uso de métodos artificiais na reprodução humana tem evoluído desde então e, dessa maneira, tem acrescido novos questionamentos que, muitas vezes, têm sido negligenciados pelo Direito, em especial pelo legislador brasileiro. $O$ fato é que a utilização das novas técnicas de reprodução (DUNSTAN; SELLER, 2003, p. 45) tem proporcionado, por meio da assistência, algumas saídas para as mais diversas modalidades de infertilidade, uma vez que, entre outros aspectos, dissociam o sexo da procriação.

A propósito, deve-se sublinhar que as modalidades de técnica reprodutiva têm historicamente evoluído desde as mais simples até as formas mais controversas (GALLO, 2015), ou seja, as advindas do emprego da fertilização in vitro (SALES, 2014, p. 19). De todas as modalidades, essa é inquestionavelmente a mais polêmica, na medida em que possibilitou diversos desdobramentos e, entre eles, as espécies de implantação e, em consequência, gravidez homóloga e heteróloga. Enquanto a primeira variante é atrelada unicamente ao casal que se submete aos tratamentos, há um insondável número de alternativas que se abrem com a segunda, pois colaciona novos atores aos processos reprodutivos.

Quando à complexidade, pode-se diferenciar em baixa e alta. À guisa de exemplificação, deve ser arrolada a transferência e a criopreservação de embriões, a doação de óvulos e de embriões, a transferência mitocondrial dos óvulos, a sub-rogação de útero etc.

Quanto à implantação, conforme outrora mencionado, há a diferenciação em homóloga e heteróloga. Deve-se salientar, ainda, que a fertilização artificial pode ser com ou sem injeção citoplasmática. De fato, as principais fases da fertilização in vitro são: a indução hormonal, a aspiração dos óvulos, a inseminação artificial (cateter), a incubação, a criopreservação dos embriões, o diagnóstico pré-implantacional (SALES, 2014, p. 67-77), a transferência embrionária, a redução embrionária, o descarte e a doação de material biológico para pesquisas científicas.

\subsection{As técnicas de fertilização in vitro no Brasil}

Considera-se como ciclo de fertilização in vitro o processo no qual a mulher é submetida à produção (estímulo ovariano) e retirada de oócitos para realizar a reprodução humana assistida. De modo geral, a média de oócitos por ciclo de fertilização in vitro possibilitará uma avaliação sobre os fatores que contribuem para a síndrome de hiperestímulo ovariano, que, de modo exemplificativo, pode causar sérios danos à paciente, inclusive levando-a, em casos extremos, ao óbito (MARTINS, 2019, on-line).

Ana Paula Caldeira, nascida em 1984, marcou a cronologia da ciência reprodutiva no Brasil (CORREIO POPULAR, 2019, on-line). De lá para cá, o cenário tem se diferenciado, seja em razão da atual conjuntura do SUS (EBC, 2018, on-line), seja em razão das atuais demandas da sociedade brasileira, que se encontra fendida em muitos aspectos, oscilando ora para uma virada liberal, ora para um abissal moralismo.

O fato é que a reprodução assistida no Brasil é fruto, em rigor, de uma série de experimentações realizadas, sobretudo, à custa de mulheres sequeladas pelas práticas abortivas clandestinas que, após contraírem segundas ou terceiras núpcias, passaram a ter o desejo pela procriação, mesmo que artificializada. ${ }^{2}$ Dessa conjuntura surgiu a modalidade eminentemente nacional da chamada "doação compartilhada de óvulos", que, em termos gerais, é feita por meio de doação de óvulos feita por mulheres jovens e pobres em troca de tratamentos em clínicas privadas.

Em uma abordagem do cenário brasileiro, o Instituto Brasileiro de Geografia e Estatística (IBGE) afirmou, recentemente, que a população do país deverá crescer até 2047, quando chegará a 233,2 milhões de pessoas. Nos anos seguintes, ela cairá gradualmente, até os 228,3 milhões em 2060 . Essas são algumas das informações da revisão 2018 da Projeção de População do IBGE, que estima demograficamente os padrões de crescimento da população do país, por sexo e idade, ano a ano, até 2060 . Em 2060, um quarto

Estima-se que, anualmente, mais de quinhentas mil mulheres se submetem a abortos clandestinos no Brasil. (EXAME, 2019, on-line). 
da população (25,5\%) deverá ter mais de 65 anos. Nesse mesmo ano, o país deverá ter 67,2 indivíduos com menos de 15 e acima dos 65 anos para cada grupo de 100 pessoas em idade de trabalhar (15 a 64 anos) (IBGE, 2018, on-line).

Adianta, ainda, que a taxa de fecundidade total para 2018 é de 1,77 filhos por mulher. Em 2060, o número médio de filhos por mulher deverá reduzir para 1,66. Entre os estados, as maiores taxas de fecundidade serão em Roraima $(1,95)$, seguidas por Pará, Amapá, Maranhão, Mato Grosso e Mato Grosso do Sul, todos com 1,80. As menores taxas deverão ser no Distrito Federal $(1,50)$ e também em Goiás, Rio de Janeiro e Minas Gerais, todos com 1,55. Já a idade média em que as mulheres têm filhos, que era de 27,2 anos em 2018, e deverá chegar a 28,8 anos em 2060.

O prognóstico é, de qualquer sorte, que se recorra cada vez mais intensamente aos meios artificiais para a reprodução, em particular em função do envelhecimento da população e das taxas apresentadas quanto à primeira gravidez, que tendem a um quadro em que as mulheres passarão a engravidar bem mais tardiamente.

O fato é que, para tentar entender essa situação, torna-se imperiosa uma atenção voltada ao Sistema Nacional de Produção de Embriões (SisEmbrio) (SBRA, 2018, on-line). O SisEmbrio foi criado pela Resolução de Diretoria Colegiada/Anvisa RDC n. ${ }^{\circ} 29$, de 12 de maio de 2008, e atualizado pela RDC $n .^{\circ}$ 23/2011, com os seguintes objetivos: conhecer o número de embriões humanos produzidos pelas técnicas de fertilização in vitro criopreservados (congelados) nos Bancos de Células e Tecidos Germinativos (BCTG), mais conhecidos como clínicas de reprodução humana assistida; atualizar as informações sobre embriões doados para pesquisas com células-tronco embrionárias, conforme demanda da Lei n. ${ }^{\circ}$ 11.105/2005 (Lei de Biossegurança) e Decreto n. ${ }^{\circ}$ 5.591/2005; divulgar informações relacionadas à produção de células e tecidos germinativos (oócitos e embriões) no Brasil - como o número de ciclos de fertilização in vitro realizados, número de oócitos produzidos, número de oócitos inseminados, número de oócitos com dois pronúcleos, número de embriões clivados, número de embriões transferidos, bem como o número de embriões descartados por ausência de viabilidade; divulgar os indicadores de qualidade dos bancos, para promover a melhoria contínua do controle de qualidade; auxiliar os inspetores sanitários a avaliar/inspecionar os BCTG; e possibilitar o acesso à população aos indicadores de qualidade dos serviços.

O uso das técnicas de reprodução assistida, regulamentado pela Resolução CFM n. ${ }^{\circ}$ 2.168/2017 (CFM, 2019, on-line), tem crescido de forma consistente no País. É o que mostra o $11 .^{\circ}$ Relatório do SisEmbrio, elaborado pela Agência Nacional de Vigilância Sanitária (Anvisa), que compilou os números dos procedimentos realizados por meio da análise dos dados de 146 (cento e quarenta e seis) BCTG referentes à produção de embriões do ano de 2017 (SBRA, 2018, on-line).

Dos 78.216 embriões congelados, mais da metade estão na Região Sudeste do país. Evidencia-se um crescimento entre os anos de 2012 a 2015, e uma redução na quantidade de embriões congelados nos anos de 2015 e 2016. Em 2017 houve um crescimento de aproximadamente 13\% (treze por cento) no número de embriões congelados em relação ao ano de 2016 (SBRA, 2018, on-line).

Desde a aprovação da Lei n. ${ }^{\circ} 11.105 / 2005$, foram doados 1363 embriões para a realização de pesquisas com células-tronco embrionárias no Brasil. A taxa de fertilização apresentou-se com valores elevados segundo essa análise e, dessa maneira, compatível com os valores sugeridos em literatura internacional, que variam entre $65 \%$ (sessenta e cinco por cento) a $75 \%$ (setenta e cinco por cento) para taxas de fertilização. A média nacional desse relatório está em $76 \%$ (setenta e seis por cento), ou seja, adequada à conjuntura científica atual (SBRA, 2019, on-line).

Outro aspecto peculiar é quanto ao nível de adesão ao sistema que tem se elevado a cada projeção anual, pois, considerando que, atualmente, a Anvisa possui o cadastro de 166 estabelecimentos, o percentual de adesão dos mesmos ao SisEmbrio é, atualmente, de $88 \%$ (oitenta e oito por cento). Ainda digno de grifo é o fato de que a atualização cadastral dos BCTG no Brasil está sob a responsabilidade de cada estabelecimento e demonstra, a partir daí, como um critério de qualificação, e acreditação da clínica e de responsabilidade social. Assim, os que não enviarem a sua produção incorrem em infração sanitária, sujeitos às penalidades previstas na Lei n. ${ }^{\circ} 6.437$, de 20 de agosto de 1977 (SBRA, 2019, on-line). 


\subsection{A proteção multinível da saúde reprodutiva e o direito ao planejamento familiar no Brasil}

A garantia da saúde reprodutiva, consequentemente, requer uma espécie de proteção multinível. Daí, a Declaração dos Direitos Humanos, em seu art. XII, estabelece: "Ninguém será sujeito à interferência em sua vida privada, na sua família, no seu lar ou na sua correspondência, nem a ataques à sua honra e reputação. Todo homem tem direito à proteção da lei contra tais interferências ou ataques" (DECLARAÇÃO UNIVERSAL DOS DH's, 2019, on-line). O planejamento familiar, que tem como uma de suas vertentes os direitos reprodutivos, foi inserido constitucionalmente como fruto de livre decisão do casal e, deste modo, imune às interferências de organismos oficiais ou privados, sendo igualmente reconhecido por múltiplos documentos internacionais como um direito.

A Constituição Federal (doravante CF/88), no art. 6. ', caput, consagra: "São direitos sociais a educação, a saúde, o trabalho, a moradia, o lazer, a segurança, a previdência social, a proteção à maternidade e à infância, a assistência aos desamparados, na forma desta Constituição". A CF/88 protege, pois, a maternidade e a saúde como direitos sociais (SARLET, 2019, p. 651) inseridos no título referente aos direitos e às garantias fundamentais.

Ela ainda expressa no art. 226, $\S 7 .^{\circ}$, que: "Fundado nos princípios da dignidade da pessoa humana e da paternidade responsável, o planejamento familiar é livre decisão do casal, competindo ao Estado propiciar recursos educacionais e científicos para o exercício desse direito, vedada qualquer forma coercitiva por parte de instituições oficiais ou privadas".

Por outro lado, as Conferências Internacionais do Cairo, sobre população e desenvolvimento, e de Pequim (Beijjing), ocorridas em 1994 e 1995, reconheceram os direitos reprodutivos como direito humano fundamental. Essencialmente, essas declarações pautam a liberdade de escolha reprodutiva, envolvendo o direito do acesso às condições de reprodução, incluindo as tecnologias reprodutivas, e o direito de não se reproduzir, sobretudo por meio do acesso aos métodos contraceptivos seguros.

Desse modo, os princípios da paternidade responsável e da dignidade da pessoa humana, consagrados na $\mathrm{CF} / 88$, se assentam no entendimento da consagração dos direitos reprodutivos como direitos fundamentais autônomos, em especial o direito ao planejamento familiar.

Não se pode olvidar que o comportamento reprodutivo de uma população é um indicativo de sua conformação social, cultural e econômica, uma vez que, além dos aspectos individuais, pode-se igualmente analisar como o Estado se ocupa de questões complexas e de grande repercussão social, como gravidez na adolescência, morbinatalidade, doenças sexualmente transmissíveis, mortalidade de parturientes, entre outros.

Esses temas, relacionados ao planejamento familiar, são de grande relevância para a população, pois interferem diretamente em sua saúde, na qualidade de vida (CAMPOS, 2008, p. 669-688), bem como no futuro da sociedade. Além disso, historicamente, no Brasil, não têm sido muito exitosas as iniciativas legislativas voltadas à superação dos dilemas que tangenciam essa temática e que, quanto à efetivação do direito constitucional, regulamentem de modo incontroverso o livre planejamento familiar. Portanto, ainda restam muitas dúvidas, em particular quando se trata de técnicas mais vanguardistas (CHILDRESS, 1990, p. 28), como a edição genética em embriões humanos, os transplantes de útero de pessoa morta, a ectogênese e a da maternidade por substituição.

De toda forma, não custa reafirmar que a Lei n. ${ }^{\circ} 9.263 / 96$ inicia por estabelecer o planejamento familiar como direito de todo cidadão. Para fins dessa lei, entende-se planejamento familiar como o conjunto de ações de regulação da fecundidade que garante direitos iguais de constituição, de limitação ou do aumento da prole pela mulher, homem ou pelo casal, restando proibida a utilização das ações a que se refere o caput para qualquer tipo de controle demográfico ou eugênico. Consiste o planejamento familiar em um conjunto de ações de atenção integral à saúde e de atendimento global ao homem, à mulher e ao casal. Suas ações devem ser preventivas e educativas, e implicam o "acesso igualitário às informações, meios, métodos e técnicas disponíveis para a regulação da fecundidade" COUNTDOWN, 2015, on-line). 


\section{Algumas reflexões sobre parentalidade no sistema jurídico brasileiro}

Os desdobramentos da reprodução humana são diversos (TEIXEIRA, 2010, p. 116-117), entre os quais destacamos os novos contornos conferidos à vivência da parentalidade (GRAZIUSO, 2018, p. 31-38). As técnicas de reprodução assistida têm impactado na compreensão desse instituto, na medida em que novas estruturas parentais surgem com os avanços biotecnológicos, a exemplo da maternidade por sub-rogação de útero e das relações que se estabelecem entre os vários atores envolvidos. Há, pois, a necessidade de compreender essa nova conjuntura familiar e social.

A relação entre pais/mães e filhos é multidimensional (BARROSO; MACHADO, 2010), e deve ser compreendida como uma experiência em contínua e ininterrupta construção e que mais tem a ver com um processo de desenvolvimento dos pais e das mães do que, propriamente, com uma responsabilidade ou $o$ exercício de uma função (PEREIRA; ALARCÃO, 2014, p. 158).

Nesse sentido, entende-se necessária a definição e a contextualização da parentalidade ${ }^{3}$ no direito brasileiro, ao mesmo tempo em que deve ser adensada a busca em demonstrar a complexidade de limitar juridicamente um conceito que está eivado de tessituras afetivas, morais, sociais e familiares.

Não parece adequado indicar uma "fórmula" que garanta uma "boa parentalidade"; contudo fazse necessário buscar o significado da vivência de uma parentalidade que se ocupe do desenvolvimento adequado do indivíduo. Para Amazonas e Braga (2006, p. 177), "independentemente da configuração familiar, o fundamental é que as crianças sejam cuidadas e desejadas, e que exista uma presença que ofereça a elas um lugar configurado com seus limites".

Barroso e Machado (2010, p. 217) acrescentam à reflexão as limitações que todas as pessoas, homens e mulheres, possuem quando, na vivência da parentalidade, se deparam com seus históricos familiares, padrões morais e religiosos, preconceitos e preconcepções: "[...] existem múltiplos determinantes do comportamento dos pais, entre os quais circunstâncias individuais, históricas e sociais que se encontram combinadas e que parecem influenciar o funcionamento parental".

Ademais, permanece no consciente coletivo um modelo ideal de família, a saber, a família nuclear composta por mãe, pai e filho(s). Esse apego a uma matriz supostamente perfeita e correta se expressa em situação de constante dívida, projetando-se como pano de fundo recorrente face às limitações próprias da vida real e não idealizada. Maria Kehl (2001, p. 36) explora essa realidade e enfatiza o papel que as pessoas adultas têm na ruptura desse equívoco para que se possa exercer a parentalidade de uma forma consciente e adequada:

[...] seja como for, cabe aos adultos que assumiram o encargo de uma criança, o risco e a responsabilidade de educá-la e prepará-la para a vida, na medida em que isto é possível. Mas a dívida para com a família perdida nos deprime, nos faz sentir que somos sempre insuficientes como pais, mães e educadores, já que de saída estamos fora do modelo da família tal como 'deveria ser' [...]E a sobrecarga dessa dívida impede que os adultos atuais, homens e mulheres, pais e mães, se autorizem e se encarreguem de acolher, criar e educar as crianças que lhes cabem, que são de sua responsabilidade, seja qual for a maneira pela qual elas foram atribuídas a eles, seja qual for a sua origem. A cultura atual nos obriga a uma dupla injunção impossível: proíbe-nos de ser e agir "como nossos pais" e nos diz, contraditoriamente, que o ideal era sê-lo. (grifo nosso).

É necessário superar o paradigma da fórmula ideal da vivência da parentalidade, especialmente quando da confrontação com as singularidades trazidas pela cisão da maternidade a partir dos avanços da biotecnologia e das técnicas de reprodução assistida. Ao longo de séculos, reafirmou-se a máxima que

Esclarece-se que parentalidade e parentesco não são sinônimos. No Direito nacional, o parentesco se estabelece em linhas e graus e está regido pelo Código Civil, e no artigo 1593 dispõe que o parentesco é natural ou civil, a depender de como se origina (se por consanguinidade ou outra origem). Para Paulo Lôbo (2018), "a relação de parentesco identifica as pessoas como pertencentes a um grupo social que as enlaça num conjunto de direitos e deveres. Para além do direito, o parentesco funda-se em sentimentos de pertencimento a determinado grupo familiar, em valores e costumes cultuados pela sociedade[...]". Neste texto, não nos ocuparemos diretamente do histórico, das espécies e das nuances do parentesco, contudo entendemos relevante essa breve conceituação para que não se confunda com a parentalidade. 
a maternidade é sempre certa, em razão do binômio gestação $\mathrm{x}$ parto, que conferia à mulher que gerou $\mathrm{e}$ pariu a inconteste condição de mãe. ${ }^{4}$

As técnicas de reprodução assistida levaram ao que Ingeborg Schwenzer (2007) denominou de split motherhood, construindo o conceito de maternidade cindida: "as biotecnologias alteraram papéis, permitindo distinguir a gestante (mãe biológica), a doadora do material (mãe genética) e a autora do projeto de maternidade (mãe intencional ou socioafetiva)" (ARAÚJO; VARGAS; MARTEL, 2013, p. 511). É nesse contexto que a maternidade por sub-rogação de útero é o ponto de inflexão das nossas ponderações acerca da parentalidade, uma vez que descortina um cenário antes sequer imaginado.

Dessa forma, é um desafio manter o ordenamento jurídico nacional em alinhamento e coerência, pois se, de um lado, não há legislação, em sentido estrito, que discipline a maternidade por sub-rogação de útero e as repercussões dela decorrentes, restando apenas a Resolução n. ${ }^{0} 2.168 / 2017$ do $C F M,{ }^{5}$ que tem sido o parâmetro para a atuação de médicos e clínicas de reprodução assistida e que possui uma diretriz muito flexível - especialmente se comparada ao disciplinamento de países como Portugal - no que se refere a quem pode ceder o útero para gestação e suas responsabilidades e deveres em relação à criança gerada.

Com efeito, a parentalidade socioafetiva é uma realidade e tem se consolidado na doutrina e jurisprudência brasileiras, além de encontrar arrimo normativo no Código Civil.

\begin{abstract}
A afetividade que foi adotada pelo direito de família brasileiro, como fundamento essencial da relação familiar, difere de outras relações afetivas, tais como a amizade, que não constitui grupo social, nem tem finalidade de constituição de família; o amor não correspondido, no qual o afeto não configura relação nem continuidade; a affectio societatis, que são as relações de confiança recíproca entre sócios de sociedade; as relações parafamiliares, em virtude de crenças religiosas e costumes, como as entre compadres e comadres. O termo "socioafetividade" conquistou as mentes dos juristas brasileiros, justamente porque propicia enlaçar o fenômeno social com o fenômeno normativo. De um lado há o fato social e de outro o fato jurídico, no qual o primeiro se converteu após a incidência da norma jurídica. A norma é o princípio jurídico da afetividade. As relações familiares e de parentesco são socioafetivas, porque congrega o fato social (socio) e a incidência do princípio normativo (afetividade) (LOBO, 2015, p. 1746-1747).
\end{abstract}

Ainda sobre o tema, convém mencionar os pressupostos da afetividade para que não gere confusões com a ideia de afeto ou de bem-querer:

\begin{abstract}
São pressupostos da socioafetividade: (1) A integração da pessoa no grupo familiar; (2) a assunção de papel parental; (3) a convivência duradoura. Difere, portanto, da relação de parentalidade, de origem biológica, pois esta é atribuída pelo direito, enquanto a relação socioafetiva é reconhecida pelo direito, a partir dos fatos consolidados da vida familiar. (LOBO, 2015, p. 1750).
\end{abstract}

Importante lembrar que a legislação brasileira comporta quatro espécies de estados de filiação, a depender da origem: "a) por consanguinidade; b) por adoção; c) por inseminação artificial heteróloga; d) por força de posse de estado de filiação" (LOBO, 2015, p. 1752).

Percebe-se que a origem genética não é mais suficiente para configurar, per si, a parentalidade, entretanto é possível/razoável afirmar que não mais remanesce relevância em conhecer a origem genética para esse fim, bem como ter expectativas de construção de uma relação parental a partir dessa identidade genética. Outrossim, importa salientar o direito à identidade genética, vez que se trata de um direito fundamental expressamente reconhecido em Portugal e de modo implícito no ordenamento jurídico brasileiro.

Nessa altura, no entanto, deve ser grifada a discussão que tem ganhado espaço no Brasil sobre a parentalidade corresponsável ou coparentalidade, na medida em que a igualdade de gênero - especialmente nas relações heterossexuais - tem no século XXI composto a agenda de Estados, da academia e da

\footnotetext{
Sabemos que poucos países se contrapõem legalmente à certeza da maternidade, como é o caso de França, todavia, o que ressaltamos é que essa "verdade" começa a ser questionada no cotidiano das relações, especialmente quando tratamos da maternidade por sub-rogação de útero (SCHWENZER; KELLER, 2016).

5 Esta resolução será analisada no ponto 4 deste texto.
} 
sociedade civil. Trata-se de um dos Objetivos de Desenvolvimento Sustentável (NAÇÕES UNIDAS, 2019, on-line) e, dessa maneira, torna-se igualmente uma pauta obrigatória para o Brasil.

Oportunamente, cumpre esclarecer que a coparentalidade passa, necessariamente, pela indicação objetiva e inequívoca de quem exercerá a parentalidade. Evidencia-se como um pressuposto para a compreensão da relação que se formará entre adulto(s) e criança(s). Diante disso, não se pode negar que as incertezas que circundam as mulheres envolvidas em protocolos de maternidade por sub-rogação de útero interferem diretamente na vivência da coparentalidade.

Frizzo et al. (2005), ao discutirem a coparentalidade no contexto da psicologia e das relações familiares, buscam apresentar um significado ao termo, reconhecendo ser ainda um conceito em construção: "A coparentalidade (coparenting) tem sido definida na literatura como um conceito que se refere à extensão na qual o pai e a mãe dividem a liderança e se apóiam nos seus papéis de 'chefes' da família, ou seja, nos papéis parentais" (FRIZZO et. al., 2005, p. 84). E ainda: "Essencialmente, a coparentalidade envolve apoio e comprometimento mútuo no exercício da parentalidade. É através desta relação que os pais podem negociar seus papéis, responsabilidades e contribuições para a criança” (FRIZZO et. al., 2005, p. 86).

Nessa medida, comprova-se que a vivência da parentalidade e a presença cada vez mais comum de uma busca pela coparentalidade são desafios para o direito e para as relações familiares e sociais, sobretudo na medida em que implica a reflexão sobre a viabilidade de se continuar avançando em biotecnologia e protocolos de reprodução assistida, a exemplo da maternidade por sub-rogação de útero e da ampliação do rol pela Resolução n. ${ }^{\circ}$ 2.168/2017 do CFM, sem a devida preocupação com a coesão e com a coerência do ordenamento jurídico, em especial no que tange aos cuidados e aos direitos das crianças e adolescentes.

\section{A regulamentação da maternidade por sub-rogação ${ }^{6}$ no direito português como um ponto de partida para a estruturação do sistema normativo brasileiro}

No Brasil, consoante mencionado acima, a Resolução n. ${ }^{\circ} 2.168 / 2017$ do CFM é a norma (em sentido amplo) que parametriza a maternidade por sub-rogação no País. As possibilidades no cenário brasileiro podem ser consideradas abrangentes, especialmente após as alterações trazidas pela referida resolução, a partir da qual a cessão temporária de útero pode ocorrer para parentes consanguíneos ascendentes e descendentes. Isto significa que avó, mãe, irmã, tia, prima, filha e sobrinha (as duas últimas apenas a partir de 2017) estão autorizadas a praticarem a sub-rogação de útero (CFM, 2017, on-line).

O manejo adequado das técnicas de reprodução assistida, em uma perspectiva ética, jurídica e social, é sabidamente difícil, pois além de envolver diversos interessados (doadora de óvulo, cedente do útero, doador de sêmen, criança etc.) alberga searas múltiplas do conhecimento e desenvolvimento humano, como medicina, embriologia, ética, filosofia, direito, biotecnologia.

É nesse sentido que se compreende que investigar experiências estrangeiras pode ser útil na proposição de opções para o Brasil; para tanto, optou-se pelo direito português como ponto de inflexão dessa análise comparativa por duas razões primordiais: 1) pela existência de lei, em sentido estrito, que versa sobre a maternidade por sub-rogação de útero; e 2) pela prolatação do recente Acórdão n. ${ }^{\circ} 225$ de 2018 pelo Tribunal Constitucional português, o qual versa sobre a (in)constitucionalidade das alterações trazidas à Lei n. ${ }^{\circ}$ 32/2006, Lei da Procriação Medicamente Assistida - LPMA.

A Lei n. ${ }^{\circ} 32$ de 2006 (Lei da Procriação Medicamente Assistida - LPMA), previa, na redação original do artigo $2 .^{\circ}$, cinco modalidades expressas de técnicas de procriação medicamente assistida: "A presente lei aplica-se às seguintes técnicas de PMA: a) Inseminação artificial; b) Fertilização in vitro; c) Injecção intracitoplasmática de espermatozóides; d) Transferência de embriões, gâmetas ou zigotos; e) Diagnóstico genético pré-implantação; [...]" (PORTUGAL, 2006, on-line).

Neste ponto do texto, utilizamos a expressão maternidade de substituição como sinônimo da expressão maternidade por sub-rogação de útero, por ser a primeira a mais utilizada pelo direito português. 
Sobre esse tema, especificamente, ressalta-se a impossibilidade de cessão de útero com fins comerciais, condizente com o teor do artigo $199, \S 4 .^{\circ}$, da CF/88:

A assistência à saúde é livre à iniciativa privada [...]. A lei disporá sobre as condições e os requisitos que facilitem a remoção de órgãos, tecidos e substâncias humanas para fins de transplante, pesquisa e tratamento, bem como a coleta, processamento e transfusão de sangue e seus derivados, sendo vedado todo tipo de comercialização.

No escopo desta investigação torna-se imperioso, inicialmente, indicar a redação original do artigo 8. ${ }^{\circ}$ da LPMA, que dispunha sobre maternidade de substituição:

1 - São nulos os negócios jurídicos, gratuitos ou onerosos, de maternidade de substituição. 2 - Entendese por «maternidade de substituição» qualquer situação em que a mulher se disponha a suportar uma gravidez por conta de outrem e a entregar a criança após o parto, renunciando aos poderes e deveres próprios da maternidade. 3 - A mulher que suportar uma gravidez de substituição de outrem é havida, para todos os efeitos legais, como a mãe da criança que vier a nascer (PORTUGAL, 2006, on line).

Destaque-se, nesse sentido, que a Lei $n .{ }^{\circ} 25$ de 2016 alterou, entre outros aspectos, a redação do artigo $8 .^{\circ}$, sobre maternidade de substituição, ${ }^{7}$ para:

1 - Entende -se por 'gestação de substituição' qualquer situação em que a mulher se disponha a suportar uma gravidez por conta de outrem e a entregar a criança após o parto, renunciando aos poderes e deveres próprios da maternidade. 2 - A celebração de negócios jurídicos de gestação de substituição só é possível a título excecional e com natureza gratuita, nos casos de ausência de útero, de lesão ou de doença deste órgão que impeça de forma absoluta e definitiva a gravidez da mulher ou em situações clínicas que o justifiquem. 3 - A gestação de substituição só pode ser autorizada através de uma técnica de procriação medicamente assistida com recurso aos gâmetas de, pelo menos, um dos respetivos beneficiários, não podendo a gestante de substituição, em caso algum, ser a dadora de qualquer ovócito usado no concreto procedimento em que é participante. 4 - A celebração de negócios jurídicos de gestação de substituição carece de autorização prévia do Conselho Nacional de Procriação Medicamente Assistida, entidade que supervisiona todo o processo, a qual é sempre antecedida de audição da Ordem dos Médicos e apenas pode ser concedida nas situações previstas no n. 2.5 - É proibido qualquer tipo de pagamento ou a doação de qualquer bem ou quantia dos beneficiários à gestante de substituição pela gestação da criança, exceto o valor correspondente às despesas decorrentes do acompanhamento de saúde efetivamente prestado, incluindo em transportes, desde que devidamente tituladas em documento próprio. 6 - Não é permitida a celebração de negócios jurídicos de gestação de substituição quando existir uma relação de subordinação económica, nomeadamente de natureza laboral ou de prestação de serviços, entre as partes envolvidas. 7 - A criança que nascer através do recurso à gestação de substituição é tida como filha dos respetivos beneficiários. 8 - No tocante à validade e eficácia do consentimento das partes, ao regime dos negócios jurídicos de gestação de substituição e dos direitos e deveres das partes, bem como à intervenção do Conselho Nacional de Procriação Medicamente Assistida e da Ordem dos Médicos, é aplicável à gestação de substituição, com as devidas adaptações, o disposto no artigo 14. ${ }^{\circ}$ da presente lei. 9 - Os direitos e os deveres previstos nos artigos $12 .^{\circ} \mathrm{e} 13 . .^{\circ}$ são aplicáveis em casos de gestação de substituição, com as devidas adaptações, aos beneficiários e à gestante de substituição. 10 - A celebração de negócios jurídicos de gestação de substituição é feita através de contrato escrito, estabelecido entre as partes, supervisionado pelo Conselho Nacional de Procriação Medicamente Assistida, onde devem constar obrigatoriamente, em conformidade com a legislação em vigor, as disposições a observar em caso de ocorrência de malformações ou doenças fetais e

\footnotetext{
O artigo 39 da mesma lei versa sobre as punições em caso de descumprimentos dos preceitos legais: "Artigo $39 .^{\circ}$ Gestação de substituição 1 Quem, enquanto beneficiário, concretizar contratos de gestação de substituição a título oneroso é punido com pena de prisão até 2 anos ou pena de multa até 240 dias. 2 - Quem, enquanto gestante de substituição, concretizar contratos de gestação de substituição a título oneroso é punido com pena de multa até 240 dias. 3 - Quem, enquanto beneficiário, concretizar contratos de gestação de substituição, a título gratuito, fora dos casos previstos nos $\mathrm{n}^{\circ \mathrm{s}} 2$ a 6 do artigo 8. $^{\circ}$, é punido com pena de prisão até 1 ano ou pena de multa até 120 dias. 4 - Quem, enquanto gestante de substituição, concretizar contratos de gestação de substituição, a título gratuito, fora dos casos previstos nos n. ${ }^{\circ} 2$ a 6 do artigo 8 . $^{\circ}$, é punido com pena de multa até 120 dias. 5 - Quem promover, por qualquer meio, designadamente através de convite direto ou por interposta pessoa, ou de anúncio público, a celebração de contratos de gestação de substituição fora dos casos previstos nos n. ${ }^{\circ s} 2$ a 6 do artigo $8 .^{\circ}$, é punido com pena de prisão até 2 anos. 6 - Quem, em qualquer circunstância, retirar benefício económico da celebração de contratos de gestação de substituição ou da sua promoção, por qualquer meio, designadamente através de convite direto ou por interposta pessoa, ou de anúncio público, é punido com pena de prisão até 5 anos. 7 - A tentativa é punível" (PORTUGAL, 2016, on-line).
} 
em caso de eventual interrupção voluntária da gravidez. 11 - O contrato referido no número anterior não pode impor restrições de comportamentos à gestante de substituição, nem impor normas que atentem contra os seus direitos, liberdade e dignidade. 12 - São nulos os negócios jurídicos, gratuitos ou onerosos, de gestação de substituição que não respeitem o disposto nos números anteriores.

Tornando-se perceptível que houve a ampliação do escopo regulatório da lei acerca da maternidade de substituição, uma vez que, no interregno de dez anos, o legislador ampliou o número de alíneas do artigo 8. ${ }^{\circ}$ de três para doze; no quadro comparativo, é possível inferir as mudanças nas três alíneas remanescentes, das quais destacamos em negrito.

\begin{tabular}{|l|l|}
\hline Lei n. ${ }^{\circ} 32$ de 2006 & Lei n. ${ }^{\circ} 25$ de 2016 \\
\hline $\begin{array}{l}\text { 1 - São nulos os negócios jurídicos, gratuitos ou onerosos, } \\
\text { de maternidade de substituição. }\end{array}$ & $\begin{array}{l}12 \text { - São nulos os negócios jurídicos, gratuitos ou } \\
\text { onerosos, de gestação de substituição que não } \\
\text { respeitem o disposto nos números anteriores. }\end{array}$ \\
\hline $\begin{array}{l}2 \text { - Entende-se por "maternidade de substituição" qualquer } \\
\text { situação em que a mulher se disponha a suportar uma } \\
\text { gravidez por conta de outrem e a entregar a criança após } \\
\text { o parto, renunciando aos poderes e deveres próprios da } \\
\text { maternidade. }\end{array}$ & $\begin{array}{l}1 \text { - Entende -se por "gestação de substituição" } \\
\text { qualquer situação em que a mulher se disponha } \\
\text { a suportar uma gravidez por conta de outrem e a } \\
\text { entregar a criança após o parto, renunciando aos } \\
\text { poderes e deveres próprios da maternidade. }\end{array}$ \\
\hline $\begin{array}{l}\text { 3 - A mulher que suportar uma gravidez de substituição } \\
\text { de outrem é havida, para todos os efeitos legais, como } \\
\text { a mãe da criança que vier a nascer. }\end{array}$ & $\begin{array}{l}7 \text { - A criança que nascer através do recurso à } \\
\text { gestação de substituição é tida como filha dos } \\
\text { respectivos beneficiários. }\end{array}$ \\
\hline
\end{tabular}

Verifica-se que, além da ordem numérica das alíneas, houve mudanças no uso de expressões, bem como de compreensões sobre a maternidade de substituição, vejamos: 1) a expressão maternidade de substituição foi substituída por gestação de substituição; 2) a presunção de que a mulher que dava à luz a criança era sua mãe foi substituída pela de que a criança é filha dos beneficiários da gestação de substituição.

Foram inseridas nove novas alíneas, transcritas acima, ipsis litteris, as quais passam pela definição de parâmetros civis do negócio jurídico (alíneas 2 a 6 e 10); pela validade e eficácia do negócio jurídico, bem como dos direitos e deveres dos envolvidos (alíneas 8 e 9); e pelos limites do negócio jurídico com ênfase ao respeito à dignidade humana (alínea 11).

Superada a indicação das mudanças trazidas à LPM, urge analisar os termos do Acordão $n .^{\circ} 225$ do Tribunal Constitucional português, que alberga uma resposta ao requerimento de trinta deputados portugueses para que fosse declarada a inconstitucionalidade das modificações trazidas pelas leis n. ${ }^{\circ} 17 / 2016$, de 20 de junho, e 25/2016, de 22 de agosto 8 à LPMA.

O foco foi as alterações apresentadas pela Lei n. ${ }^{\circ} 25$, por versarem sobre a maternidade de substituição, esclarecendo, de início, que o referido Acórdão intentou contextualizar, no marco do ordenamento jurídico português, as três questões centrais que representariam afronta à Constituição portuguesa e, desta forma, seriam dispositivos a serem declarados inconstitucionais, todos da LPMA: 1) artigo $8 .^{\circ}$, sob a epígrafe Gestação de substituição; 2 ) o artigo $15 .^{\circ}$, sob a epígrafe da Confidencialidade; e 3 ) artigo $20 .^{\circ}$, sob a epígrafe da Determinação da parentalidade (PORTUGAL, 2018, on-line).

O Tribunal Constitucional português (2018, on-line) arrimou suas primeiras considerações na Constituição da República Portuguesa, que incumbe à lei a regulamentação das técnicas de reprodução assistida, nos termos do $n .^{\circ}$ 2, alínea e: "incumbe ao Estado (...) regulamentar a procriação assistida em termos que salvaguardem a dignidade da pessoa humana".

8 Em 25 de julho de 2017 houve nova alteração à LPMA, pela Lei n. ${ }^{\circ}$ 58/2017, a qual versa sobre o destino dos espermatozoides, ovócitos, tecido testicular e tecido ovárico, motivo pelo qual não será objeto de análise neste texto (PORTUGAL, 2017, on-line). 
O Tribunal resgatou na decisão o direito comparado, apresentando as diretrizes normativas centrais de vários países europeus (Áustria, Alemanha, França, Itália etc.) para ao final apresentar o supedâneo constitucional português para as técnicas de reprodução assistida, que vem sendo, historicamente, o princípio da dignidade da pessoa humana, o qual se oporia a qualquer medida que aproximasse a gestação de substituição de uma prática comercial:

[...] a primeira, e fundamental, questão de constitucionalidade que se coloca a propósito da gestação de substituição é a de saber se, como sustentam os requerentes, os negócios jurídicos legalmente previstos que têm por objeto a utilização temporária do corpo de um ser humano (a gestante) para gerar outro (a criança a nascer por via de tal modo de procriação) não serão incompatíveis com a dignidade da pessoa humana. (PORTUGAL, 2018, on-line).

A decisão ressalta, ainda, os termos do requerimento da inconstitucionalidade:

[...] no entender dos requerentes, a gestação de substituição consubstancia uma inaceitável mercantilização do ser humano, quer no que respeita à gestante, cujo corpo se transformaria num objeto ao serviço dos beneficiários, quer relativamente à criança, que desde antes do nascimento seria objeto de um negócio jurídico [...] (PORTUGAL, 2018, on-line).

O acórdão declarou inconstitucional ${ }^{9}$ parte do artigo $8 .^{\circ}$ da Lei $n .{ }^{\circ} 32 / 2006$, a saber: os números 4,7 , 8, 10, 11, 12. Resta, portanto, explícito que o Tribunal Constitucional português, no Acórdão n. ${ }^{\circ} 225 / 2018$, ratificou um entendimento que busca alinhar os direitos reprodutivos, especialmente das mulheres, e os direitos das crianças. Esclarece-se que o Tribunal se contrapôs às alterações legislativas trazidas pelas Leis n 17 e 25, ambas de 2016, e se alinhou ao Conselho Nacional de Ética para as Ciências da Vida CNECV, o qual, desde 2016, vem se manifestando no sentido de priorizar os direitos das crianças na seara da reprodução assistida. ${ }^{10}$

Ora, esta alteração legislativa trouxe, na verdade, uma «mudança de paradigma da utilização das técnicas da $P M A »$ - palavras do CNECV -, pois deslocou o foco de toda a proteção exclusivamente para a mulher, desconsiderando aquele conjunto de direitos que constitui o mais importante valor a salvaguardar, e em relação aos quais o Estado tem um particular dever de proteção: os direitos da criança. Se o direito a constituir família e a ter filhos é constitucionalmente protegido, também o é o direito a conhecer-se cabalmente a sua identidade - também a genética - e, entre um e outro, deverá ser o primeiro a ceder, e não o contrário, como sucede nesta lei.

Diante dos excertos apresentados e das análises realizadas, evidencia-se que o direito português tem limitado o uso das técnicas de reprodução assistida, como os protocolos relacionados à maternidade por

\footnotetext{
"Pelos fundamentos expostos, o Tribunal decide: a) Declarar a inconstitucionalidade, com força obrigatória geral, das normas dos $\mathbf{n}$. ${ }^{\mathbf{s}} \mathbf{4}$, 10 e 11 do artigo $8^{\circ}$ da Lei n. ${ }^{\circ} 32 / 2006$, de 26 de julho, e, consequentemente, das normas dos n..$^{\circ} 2$ e 3 do mesmo artigo, na parte em que admitem a celebração de negócios de gestação de substituição a título excecional e mediante autorização prévia, por violação do princípio da determinabilidade das leis, corolário do princípio do Estado de direito democrático, e da reserva de lei parlamentar, decorrentes das disposições conjugadas dos artigos $2 .^{\circ}, 18 .^{\circ}, \mathrm{n} .^{\circ} 2$, e $165, \mathrm{n} .^{\circ} 1$, alínea b), da Constituição da República Portuguesa, por referência aos direitos ao desenvolvimento da personalidade e de constituir família, consagrados nos seus artigos $26 .^{\circ}, \mathrm{n} .{ }^{\circ} 1$, e $36 .^{\circ}, \mathrm{n} .^{\circ} 1$; b) Declarar a inconstitucionalidade, com força obrigatória geral, da norma do $n .^{\circ} 8$ do artigo $8^{\circ}$ da Lei n. ${ }^{\circ} 32 / 2006$, de 26 de julho, em conjugação com o n. 5 do artigo $14 .^{\circ}$ da mesma Lei, na parte em que não admite a revogação do consentimento da gestante de substituição até à entrega da criança aos beneficiários, por violação do seu direito ao desenvolvimento da personalidade, interpretado de acordo com o princípio da dignidade da pessoa humana, e do direito de constituir

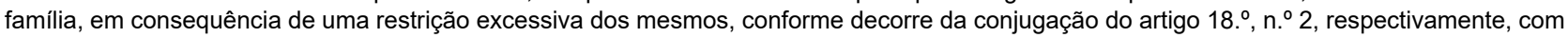
os artigos $1 .^{\circ}$ e $26 .^{\circ}$, n. ${ }^{\circ}$, por um lado, e com o artigo $36 .^{\circ}, \mathrm{n} .{ }^{\circ} 1$, por outro, todos da Constituição da República Portuguesa;

c) Declarar a inconstitucionalidade consequente, com força obrigatória geral, da norma do n. $^{\circ} 7$ do artigo $8 .^{\circ}$ da mesma Lei; d) Declarar a inconstitucionalidade, com força obrigatória geral, da norma do $\mathbf{n} .^{\circ} 12$ do artigo $8 .^{\circ}$ da Lei $n .^{\circ} 32 / 2006$, de 26 de julho, por violação do direito à identidade pessoal da criança previsto no artigo $26 .^{\circ}, \mathrm{n} .^{\circ} 1$, da Constituição da República Portuguesa, do princípio da segurança jurídica decorrente do princípio do Estado de direito democrático, consagrado no artigo $2 .^{\circ}$ da mesma Constituição, e, bem assim, do dever do Estado de proteção da infância, consagrado no artigo $69 .^{\circ}, \mathrm{n} .^{\circ} 1$, do mesmo normativo;[...]"(Grifamos).

10 A decisão sobre a utilização de técnicas de PMA deve estar subordinada ao primado do ser humano, princípio fundamental que rejeita a sua instrumentalização, e consagra a dignidade do ser humano e consequente proteção dos seus direitos, em qualquer circunstância, face às aplicações ciência e das tecnologias médicas (Convenção sobre os Direitos do Homem e Biomedicina). No âmbito da aplicação das técnicas de PMA deve, assim, valorizar-se a condição do ser que irá nascer que, pela natureza e vulnerabilidade é quem é mais carecido de proteção. Devem ainda ser tidos em consideração os direitos do/a filho/a à sua identidade pessoal, ao conhecimento das suas origens parentais, bem como a conhecer eventuais riscos para a sua saúde associados aos processos tecnológicos usados na sua geração. A serem aprovados, os Projetos de Lei contrariam o que o sistema da filiação tem vindo a assumir nas últimas décadas no sentido da progressiva eliminação de assentos de nascimento omissos quanto a um dos progenitores, no suposto da realização dos direitos do/a filho/a. (CNECV, 2016, on-line, p. 11).
} 
sub-rogação de útero, sob a justificativa de que há de haver um equilíbrio e, em particular, um alinhamento entre os direitos das pessoas adultas (homens e mulheres que buscam essa técnica para a realização do projeto parental) e o direito das crianças, perfazendo uma constelação em que todos os atores devem ter resguardada a sua dignidade.

\section{Conclusão}

À guisa de conclusão, impende afirmar que a parentalidade é conformada pelo cotidiano das relações, pela personalidade e pelos anseios dos envolvidos e igualmente pelas diversas formas de organização familiar em uma maneira dinâmica e única. Portanto, não há um ideal quando se trata de projeto parental. Por outro lado, há contornos jurídicos que precisam estar presentes e em consonância com os direitos da criança e do adolescente e, obviamente, com o catalogo dos direitos fundamentais a que todos fazem jus, engendrando um contexto de respeito ao ordenamento jurídico nacional.

A parentalidade está diretamente relacionada à proteção e à promoção da infância, tendo em conta suas repercussões na vida da criança e da família (mononuclear ou não) e, desta forma, vinculada ao bemestar dos envolvidos, especialmente, por serem pessoas em desenvolvimento (físico, psíquico, social...). Em que pese a emergência, por fluxos contínuos, de novidades no campo da biotecnologia, há sempre de preponderar o melhor interesse daquele que será gerado, sobretudo para que não se torne uma espécie de produto na sanha consumerista atual.

O que se torna perceptível no Brasil, a partir da constatação do vácuo legislativo face à existência de uma resolução do Conselho Federal de Medicina (CFM) extremamente flexível e abrangente em relação à maternidade por sub-rogação de útero - especialmente em contraponto com o direito português, consoante restou demonstrado- há um desalinhamento entre os avanços das técnicas de reprodução assistida e os parâmetros normativo-jurídicos acerca da coparentalidade responsável. A propósito, trata-se de uma visão antiquada, pois se caracteriza pelo enfoque eminentemente biomédico, ou seja, ao arrepio, e.g., da trajetória advinda do pensamento bioético e da exigência por uma alteração de paradigma na área da saúde.

Dessa forma, prefigura-se a essencialidade de um diálogo profícuo entre as instituições que representam os interesses de todos os profissionais da saúde e dos pacientes, ou seja, que amplamente possibilite o alinhavo de instituições como o CFM com outras entidades que se ocupem em discutir, dentre outros pontos, os aportes da proteção dos direitos das crianças, bem como as diretrizes normativas constitucionais brasileiras, destacando-se o papel nuclear do Ministério Público nessa seara.

Não se pode olvidar, de todo modo, os inúmeros benefícios advindos do emprego das técnicas de reprodução assistida, contudo, no Brasil, parece inconteste que o avanço no que toca às biotecnologias não veio acompanhado de discussões ético, morais e jurídicas elementares à confirmação do uso desse instrumental como algo relevante e adequado às relações pessoais e familiares no panorama nacional. Não se pode apostar na vedação ao uso, mas posiciona-se pelo emprego parcimonioso e regulamentado a partir de uma ampla participação popular que, ao tempo que não se caracteriza como um óbice ao exercício da liberdade científica consagrada constitucionalmente, passe a contemplar de modo amplo os diversos aspectos que dessa problemática parecem emergir.

Oportuno ressaltar que se trata de tema de alta complexidade que, indubitavelmente, tende a ter uma abrangência cada vez maior em razão dos dados apontados pelo IBGE referentes ao envelhecimento da população e do adiamento quanto ao planejamento familiar, carecendo de certa urgência quanto ao seu enfrentamento.

De qualquer sorte, trata-se de reafirmar o planejamento familiar como um direito humano e fundamental que, em certa medida, encontra a necessidade de uma configuração em que os limites eficaciais na casuística sejam equivalentes à responsabilidade para com a pessoa humana e, portanto, não se expresse pura e simplesmente como um fetiche contemporâneo. 
O exemplo português, então, na medida em que se projeta como uma ruptura na tendência atual quanto ao uso irrestrito da ciência por vezes mediada por certos vieses eugênicos, fornece luminares para a reflexão sobre o tema. Tal medida, fruto do esforço jurídico lusitano, expressa de modo inequívoco uma constelação em que o tracejo jurídico impõe uma abertura no automatismo atual quanto ao uso irreflexivo da biotecnologia, ensejando uma oportunidade de ponderação que contemple tanto os direitos quanto os deveres que, na medida da responsabilidade, da dignidade e da solidariedade, configuram a relação parental em seu sentido contemporâneo.

Portanto, essa experiência portuguesa, além de clarificar a relevância da existência de padrões normativos advindos de amplo debate nacional aponta para um momento histórico em que não se pode olvidar que a ausência e a omissão do poder legislativo brasileiro podem ser igualmente reconhecidas como formas de posicionamento que, embora inapropriadas, tendem a repercutir com amplas e ainda inalcançáveis consequências que carecem de urgente reflexão para além do medo, visando à esperança e ao solidarismo.

\section{Referências}

A POLÊMICA em torno do transplante de útero. Made for minds. Disponível em: https://www.dw.com/ptbr/a-pol\%C3\%AAmica-em-torno-do-transplante-de-\%C3\%BAtero/av-45333870?maca=pt-BR-Whatsappsharing. Acesso em: 02 dez. 2018.

ABORTO clandestino e drama para milhões de mulheres no Brasil. Exame. 25 ago. 2018. Disponível em: https://exame.abril.com.br/brasil/aborto-clandestino-e-drama-para-mais-de-meio-milhao-demulheres-no-brasil/. Acesso em: 26 fev. 2019.

AGÊNCIA IBGE NOTÍCIAS. Projeção da população 2018: número de habitantes do país deve parar de crescer em 2047. IBGE, 01 ago. 2018. Disponível em: https://agenciadenoticias.ibge.gov.br/agenciasala-de-imprensa/2013-agencia-de-noticias/releases/21837-projecao-da-populacao-2018-numero-dehabitantes-do-pais-deve-parar-de-crescer-em-2047. Acesso em: 10 out. 2018.

ANDERSON, J.; RAINIE, L.; LUCHSINGER, A. Artificial Intelligence and the Future of Humans. Pew Research Center. 10 dec. 2018. Disponível em: http://www.pewinternet.org/2018/12/10/artificialintelligence-and-the-future-of-humans/. Acesso em: 26 fev. 2019.

CAMPOS, G.W.S. Co-construção de autonomia: o sujeito em questão. In: CAMPOS, G.W.S. et al. Tratado de saúde coletiva. São Paulo: Hucitec, 2008, p. 669-688.

CHILDRESS, James F. Reproductive interventions: theology, ethics, and public policy. In: CURRAN, Charles E. (ed.). Moral Theology: challenges for the future: essays in honor of Richard A. McCormick. New York: Paulist Press, 1990. p. 285-309.

CONSELHO FEDERAL DE MEDICINA (Brasília). Resolução CFM n. 2.168/2017, de 21 de setembro de 2017. Adota as normas éticas para a utilização das técnicas de reprodução assistida. Brasília: Conselho Federal de Medicina, 2017. Disponível em: https://sistemas.cfm.org.br/normas/visualizar/ resolucoes/BR/2017/2168. Acesso em: 26 fev. 2019

CONSELHO NACIONAL DE ÉTICA PARA AS CIÊNCIAS DA VIDA (Lisboa). Relatório e Parecer

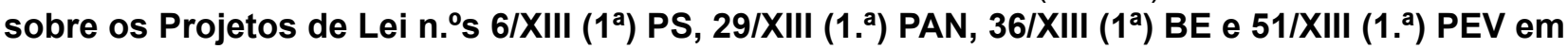
matéria de Procriação Medicamente Assistida (PMA) e 36/XIII (1a) BE em matéria de Gestação de Substituição (GDS). Lisboa: CNECV, 2016. Disponível em: http://www.cnecv.pt/admin/files/data/ docs/1461943756_P\%20CNECV\%2087_2016_PMA\%20GDS.pdf. Acesso em: 30 ago. 2018.

COUNTDOWN 2015 EUROPE. Planeamento familiar numa perspectiva de direitos humanos. Disponível em: http://www.countdown2030europe.org/storage/app/media/IPPF_FactSheet-6_ HumanRights-PT.pdf. Acesso em: 26 fev. 2019.

DECLARAÇÃO Universal dos Direitos Humanos. Disponível em: https://declaracao1948.com.br/ declaracao-universal/declaracao/?gclid=CjOKCQiAh9njBRCYARIsALJhQkGuqbXs2M8LcDak_ yj5t1iBpQfFfEWLrLfT9HIvBBwbJRVZL_JR2XsaAsa5EALw_wcB. Acesso em: 26 fev. 2019. 
DUNSTAN, G.R.; SELLER, Mary J. (ed.). The status of the human embryo: perspectives from moral tradition. London: Oxford University Press, 1988.

DWORKIN, R. Domínio da vida: aborto, eutanásia e liberdades individuais. São Paulo: Martins Fontes, 2003, p. 45.

LABOISSIĖRE, Paula. Quase 90\% dos brasileiros consideram saúde péssima, ruim ou regular. Agência Brasil, Brasília, 26 jun. 2018. Disponível em: http://agenciabrasil.ebc.com.br/saude/noticia/2018-06/para89-dos-brasileiros-saude-e-considerada-pessima-ruim-ou-regular. Acesso em: 27 fev. 2019.

FRIZZO, Giana Bitencourt et al. O conceito de coparentalidade e suas implicações para a pesquisa e para a clínica: implication for research and clinical practice. Revista brasileira crescimento desenvolvimento humano, São Paulo, v. 15, n. 3, p. 84-93, dez. 2005. Disponível em http://pepsic. bvsalud.org/scielo.php?script=sci_arttext\&pid=S0104-12822005000300010\&lng=pt\&nrm=iso. Acesso em: 29 nov. 2018.

GALLO, G. et al. Structural basis for dimer formation of the CRISPR-associated protein Csm2 of Thermotoga maritima. FEBS Journal, v. 283, p. 694-703, 2016. Disponível em: https://febs.onlinelibrary. wiley.com/doi/abs/10.1111/febs.13621. Acesso em: 29 nov. 2018.

GALLO, G. et al.Purification, crystallization, crystallographic analysis and phasing of the CRISPRassociated protein Csm2 from Thermotoga maritima. Acta Cryst, [S.], p. 1223-1227. out. 2015. Structural Biology Communications, F71. Disponível em: http://scripts.iucr.org/cgi-bin/ paper?S2053230X15014776. Acesso em: 26 fev. 2019.

GRAZIUSO, Bruna Kern; MEDEIROS, Fernanda Luiza Fontoura; CARLOS, Paula Pinhal de. Mães de pet: maternidade e especismo. Canoas: Unilasalle, 2018.

NAÇÕES UNIDAS NO BRASIL. Igualdade de gênero: alcançar a igualdade de gênero e empoderar todas as mulheres e meninas. In: NAÇÕES UNIDAS NO BRASIL. Documentos Temáticos, Brasília: ONU, 2017. p. 1-18. Disponível em: https://nacoesunidas.org/wp-content/uploads/2017/06/DocumentoTem\%C3\%A1 tico-ODS-5-Igualdade-de-Genero-editorado_11junho2017.pdf. Acesso em: 26 fev. 2019.

KEHL, Maria. Lugares do feminino e do masculino na família. In: COMPARATO, Maria Cecilia Mazzilli; MONTEIRO, Denise de Sousa. Feliciano. A criança na contemporaneidade e a psicanálise: família e sociedade, diálogos interdisciplinares. São Paulo: Casa do Psicólogo, 2001. p. 29-38.

LÔBO, Paulo. Direito civil: famílias. 8. ed. São Paulo: Saraiva, 2018, v. 5.

LÔBO, Paulo. Socioafetividade: o estado da arte no direito da família brasileiro. Revista Jurídica LusoBrasileira, Lisboa, ano 1, n.1, p. 1743-1759, 2015.

LOUISE Brown world's first IVF baby's family archive unveiled. BBC-News. Disponível em: https://www. bbc.com/news/uk-england-bristol-44940929. Acesso em: 27 fev. 2019.

MARTINS ACS, Silva. Perfil epidemiológico de mortalidade materna. Revista Brasileira de Enfermagem, Brasília, v. 71, supl. 1, p. 677-683, 2018. Disponível em: http://www.scielo.br/pdf/reben/ v71s1/pt_0034-7167-reben-71-s1-0677.pdf. Acesso em: 26 fev. 2019.

ORGANIZAÇÃO MUNDIAL DA SAÚDE. Guia de implantação dos critérios médicos de elegibilidade e das recomendações da OMS para o uso de contracepção. Ginebra: OMS, 2018. Disponível em: https://apps.who.int/iris/bitstream/handle/10665/272758/9789247513573-por.pdf?ua=1. Acesso em: 26 fev. 2019.

PEREIRA, Dora Isabel Fialho; ALARCÃO, Madalena. Parentalidade minimamente adequada: contributos para a operacionalização do conceito. Análise Psicológica, Lisboa, v. 32, n. 2, p. 157171, jun. 2014. Disponível em: http://www.scielo.mec.pt/scielo.php?script=sci_arttext\&pid=S0870$82312014000200003 \&$ Ing=pt\&nrm=iso. Acesso em: 29 nov. 2018.

PORTUGAL. Lei n 25/2016, de 22 de agosto de 2016. Diário da República: $1^{\text {a }}$ série, [S.I.], n. 160, p. 2775-2777, 22 ago. 2016. Disponível em: https://dre.pt/application/conteudo/75177806. Acesso em: 30 ago. 2018. 
PORTUGAL. Lei n 32/2006, de 26 de julho de 2006. Diário da República: $1^{a}$ série, [S.I.], n. 143, p. 5245-5250, 26 jul. 2006. Disponível em: https://dre.pt/application/conteudo/539239. Acesso em: 24 jul. 2018.

PORTUGAL. Lei no 58/2017, de 25 de julho de 2017. Diário da República: $1^{a}$ série, [S.I.], n. 142, p. 3915-3922, 25 jul. 2017. Disponível em: https://dre.pt/application/conteudo/107745743. Acesso em: 24 jul. 2018.

PRIMEIRO bebê de proveta. Correio Popular. Disponível em: http://correio.rac.com.br/_ conteudo/2014/10/capa/nacional/212224-primeiro-bebe-de-proveta-do-brasil-e-da-al-faz-30-anos.html. Acesso em: $27 \mathrm{fev}$. 2019.

SALES, Gabrielle Bezerra. Überzählige Embryonen in der Reproduktionsmedizin: ein Rechtsvergleich zwischen Deutschland und Brasilien. In: ALBERTS, Marion et al.(org.). Überzählige Embryonen in der Reproduktionsmedizin: ein Rechtsvergleich zwischen Deutschland und Brasilien. Band 13. BadenBaden: Nomos, 2014. p-p?

SARLET, Ingo Wolfgang. Direitos fundamentais em espécie. In: SARLET, Ingo Wolfgang; MARINONI, Luiz Guilherme; MITIDIERO, Daniel. Curso de Direito Constitucional. 8.ed. São Paulo: Saraiva, 2019. p. 417-841.

SCHWENZER, Ingeborg. Tensions between legal, biological and social conceptions of parentage. Antwerpen: Intersentia, 2007.

SCHWENZER, Ingeborg; KELLER, Tomie. The changing concept of 'family' and challenges for family law in Switzerland. In: SCHERPE, Jens M. (ed.). European family law the changing concept of 'family' and challenges for domestic family law. Cheltenham: Edward Elgar, 2016. v. 2. p. 309-334.

SOCIEDADE Brasileira de Reprodução Assistida - SBRA. Disponível em: http://sbra.com.br/wp-content/

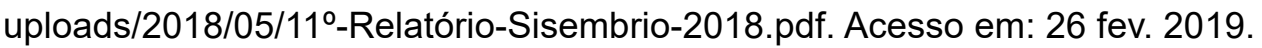

TEIXEIRA, Ana Carolina Brochado. Saúde, corpo e autonomia privada. Rio de Janeiro: Renovar, 2010. PORTUGAL. Tribunal Constitucional Portugal. Acórdão n 225/2018. Relator: Conselheiro Pedro Machete, Disponível em: http://www.tribunalconstitucional.pt/tc/acordaos/20180225.html. Acesso em: 28 ago. 2018.

Recebido em: 28/10/2019

Aprovado em: 16/01/2020 